\title{
Somogy megye poloskafaunája (Heteroptera)
}

\author{
KondOROSY ELód
}

Kondorosy E.: Bug fauna of Somogy county (Heteroptera)

Abstract: The checklist of Heteroptera of Somogy County gives an account of 448 species, representing $51 \%$ of the Hungarian fauna. The majority of the data, unpublished or published by the author, is based on the author's own collection. The investigation of the bug fauna of Somogy County showed a higher percentage of the species with Mediterranean distribution than most of the investigations on the Hungarian bug fauna.

\section{Bevezetés}

Somogy megyében élő poloskákról az elsố adatokat a Fauna Regni Hungariae (HORVÁTH 1900) szolgáltatja, amely mindössze 10 fajt (Kleidocerys resedae, Dimorphopterus spinolae, Dictyla rotundata, Monosteira unicostata, Nagusta goedelii, Anthocoris minki, Dufouriellus ater, Polymerus brevicornis, Megalocoleus exsanguis, Monosynamma bohemani) említ, melyek zöme más forrásból nem került eló (ez persze nem jelenti azt, hogy e fajok azóta kivesztek a megyéból). Természetesen sokkal több faj ismert volt már akkor is a megyéból, de a gyakoribb fajok lelőhelyeit a mú nem részletezi. További két fajt (Trigonosoma trigonum, Allodapus montandoni) említ Horváth (1907) a Fauna Regni Hungariae kiegészítésében. A 9 azóta elô nem került faj közül országosan is ritka a Monosteira unicostata és a Nagusta goedelii.

Somogy megye vagy annak egy részének poloskafaunájáról a Barcsi Borókás faunájának felméréséig nem született önálló publikáció (VÁSÁRHELYI 1985), csak más cikkekben történt említés alkalmakként néhány Somogy megyében gyúitốtt fajról.

Az ötvenes években HaLÁszfy (1954, 1955) kezdte el a budapesti Természettudományi Múzeum poloskagyújteményének feldolgozását a Pentatomoidea alrenddel, mikor is a Cydnidae és Scutelleridae családokból 6, illetve 5 fajt talált meg Somogyból . E fajok a Microporus nigritus, Geotomus elongatus és punctulatus, Legnotus limbosus és picipes, valamint a Canthophorus melanopterus földipoloskák, illetve a pajzsospoloskák közül az Odontoscelis fuliginosa, Odontotarsus purpureolineatus, Psacasta exanthematica, továbbá az Eurygaster maura és testudinaria voltak.

Soós (1959) a múzeumi példányok feldolgozása során 9 búvárpoloskát talált Somogy megyében (Cymatia coleoptrata, Corixa punctata, Paracorixa concinna, Hesperocorixa linnaei, Sigara falleni, lateralis, nigrolineata, striata és limitata). Ugyancsak Soós (1973) a Spilostethus pandurus cirkumtropikus Lygaeidae faj máig is egyetlen hazai adatát közli. VÂSÁRHELYI (1974a) két csipkéspoloskát (Elasmotropis testacea és Tingis ampliata) és (VÁSÁRHELYI 1974b) egy faunára új bödepoloskát (Coptosoma mucronatum) közöl somogyi lelóhelyekról, majd (VÁ- 
SÁRHELYI 1979) madárfészekból gyứjtött fecskepoloskáról (Oeciacus hirundinis) ír.

BENEDEK (1970) több poloskacsalád múzeumi anyagát is publikálta, esetenként jó pár somogyi lelóhellyel, így a Leptopodomorpha és Gerromorpha alrendeket, melyek hazai fajai közül Somogyban elókerült a Saldula calbum, melanoscela, opacula, pallipes, palustris, pilosella, Gerris odontogaster, thoracicus, Mesovelia furcata, Hebrus pusillus és Hydrometra stagnorum. A tolvajpoloskák közül BenedeK (1969) 8 fajt talált meg Somogy megyében: Prostemma aeneicolle, Himacerus apterus és mirmicoides, Nabis brevis, ferus, pseudoferus, punctatus és rugosus. A rablópoloskák feldolgozása során (BENEDEK 1968) 7 fajt talált meg Somogy megyében (Pygolampis bidentata, Reduvius personatus, Pirates hybridus, Rhynocoris annulatus, iracundus, Coranus subapterus (ma C. kerzhneri), Phymata crassipes). Ugyancsak BeNEDEK (1967) közölte saját és mások Pentatomoidea gyújtésének anyagát, ebben 32 faj esetében említett Somogy megyei lelóhelyet. További három címerespoloska (Eurydema spp.) lelóhelyeit külön cikkben közölte (BENEDEK 1966).

Máig három publikáció foglalkozott teljesen vagy túlnyomórészt Somogy megyei poloskákkal, valamennyi egy-egy természetvédelmi indíttatású faunafeltáró munka részeként (FölDESSY, 1992; KONDOROSY és FÖLDESSY, 1998 és VÁSÁRHELYI, 1985). Mindezeken az irodalmakon túlmenóen zömmel a következó anyagokra támaszkodtam:

- saját 1989 és 1993 közötti szántóföldi felvételezéseim anyaga;

- saját 1995 és 1997 közötti Dráva menti gyújtéseim anyaga (DDNP alapállapot-felmérés keretében);

- Abrahám Levente 1997 és 1999 között gyújiött anyaga;

- saját 1993 és 1997 közötti kis-balatoni gyújtéseim anyagából a Somogy megye területén gyújiött anyag;

- saját 1998-ban, egy hatástanulmány készítéséhez Vízvár környékén gyújtött anyagom.

Nagyrészt átnéztem a Magyar Természettudományi Múzeum Állattárának anyagát is.

E lista célja a Somogy megye területéról eddig ismert poloskafajok összeszedése, a kevés eddigi ismeret miatt zömmel nem publikált anyagok alapján, mely egyben alapul szolgálhat a további kutatásokhoz is.

Arról persze nincs szó, mintha ez a lista a megyében éló fajokat csaknem teljes számban tartalmazná. A jelenleg hazánkból kimutatott 826 poloskafajnak több mint a felét, 448 fajt ismerünk eddig Somogy megyéból, de nagy valószínúséggel a hazai fajok legalább 80\%-a, több mint 650 faj él a megyében. A még ki nem mutatott mintegy 200 faj többsége viszonylag ritka, várhatóan szórványos előfordulású a megyében, de még gyakori fajok is vannak köztük, amelyek hiánya a véletlennek és a sok más csoporthoz viszonyítva kevés kutatásnak köszönhető.

Az elốkerült fajok egy része innen vált ismertté Magyarországon. Ezek között vannak olyanok, amelyek egyidejúleg vagy azóta más lelổhely(ek)ról is elókerültek: Dicyphus constrictus, Strongylocoris luridus, Orthotylus viridinervis, Criocoris nigripes, Psallus pardalis, Amblytylus albidus (valamennyi Miridae), Himacerus boops (Nabidae), de vannak olyanok is, amelyeket egyelóre csak innen ismerünk. Ezek közül valószínú, hogy a Dicyphus pallidus és Grypocoris sexguttatus fajok számos helyen előfordulnak az országban, de a Cryptostemma alienum, Capsodes mat, Psallus anaemicus fajok feltehetően hazánkban szúk elterjedésúek (persze néhány más megyéból, pl. Baranyából való előkerülésük ezek- 
nek is valószínú). Utóbbi három közül a Cryptostemmatidae családba tartozó Cryptostemma alienum boreomontán elterjedésú, így inkább a nyugati határszélen várható, míg a másik két faj mediterrán és itt elterjedésének északi határát éri el.

A felsoroltakon kívül több további olyan fajt ismerünk, amely hazánkban csak néhány lelőhelyről ismert. Az inkább boreomontán elterjedésú fajok közül ilyen pl. a Chartoscirta elegantula, Myrmedobia exilis, Bryocoris pteridis, Apolygus limbatus, Monalocoris filicis, Pantilius tunicatus, Nabicula limbata, Berytinus consimilis, Rhacognathus punctatus.

Számos ritka mediterrán-pontomediterrán faj mellett (Dionconotus confluens, Phytocoris meridionalis, Amblytylus glaucicollis, Metapterus linearis, Trapezonotus ullrichi, Menaccarus arenicola, Stagonomus amoenus) néhány ritka európai vagy palearktikus elterjedésú fajt is kiemelhetünk, mint a Chartoscirta cocksi, Tropidophlebia costalis vagy Codophila varicornis.

A fajok tudományos nevét KONDOROSY (1999) rendszertani listája lapján közlöm.

\section{Somogy megye faunalistája}

DIPSOCOROMORPHA

\section{Cryptostemmatidae}

Cryptostemma alienum (Herrich-Schäffer, 1835)

\section{NEPOMORPHA}

Nepidae

Nepinae

Nepa cinerea Linnaeus, 1758

Ranatrinae

Ranatra linearis (Linnaeus, 1758)

\section{Corixidae}

Micronectinae

Micronecta scholtzi (Fieber, 1851)

Cymatiainae

Cymatia coleoptrata (Fabricius, 1776)

Cymatia rogenhoferi (Fieber, 1864)

\section{Corixinae}

Callicorixa praeusta (Fieber, 1848)

Corixa affinis (Leach, 1785)

Corixa punctata (Illiger, 1807)

Hesperocorixa linnei (Fieber, 1848)

Hesperocorixa sahlbergi (Fieber, 1848)

Paracorixa concinna (Fieber, 1848)

Sigara falleni (Fieber, 1848)

Sigara lateralis (Leach, 1818)

Sigara limitata (Fieber, 1848)

Sigara nigrolineata (Fieber, 1848)

Sigara striata (Linnaeus, 1775)
Naucoridae

Ilyocoris cimicoides (Linnaeus, 1758)

Notonectidae

Notonecta glauca Linnaeus, 1758

Notonecta viridis Delcourt, 1909

Pleidae

Plea minutissima Leach, 1817

GERromorphA

Mesoveliidae

Mesovelia furcata Mulsant et Rey, 1852

Hydrometridae

Hydrometra gracilentum Horváth, 1899

Hydrometra stagnorum (Linnaeus, 1758)

Hebridae

Hebrus pusillus (Fallén, 1807)

Veliidae

Microvelia pygmaea (Dufour, 1833)

Microvelia reticulata (Burmeister, 1835)

Gerridae

Gerris (Aquarius) paludum Fabricius, 1794

Gerris argentatus Schummel, 1832

Gerris gibbifer Schummel, 1832

Gerris lacustris (Linnaeus, 1758)

Gerris odontogaster (Zetterstedt, 1828)

Gerris thoracicus Schummel, 1832 


\section{LEPTOPODOMORPHA}

Saldidae

Chartoscirta cincta (Herrich-Schäffer, 1842)

Chartoscirta cocksi (Curtis, 1835)

Chartoscirta elegantula (Fallén, 1807)

Saldula c-album (Fieber, 1859)

Saldula melanoscela (Fieber, 1859)

Saldula opacula (Zetterstedt, 1839)

Saldula pallipes (Fabricius, 1794)

Saldula palustris (Douglas \& Scott, 1874)

Saldula pilosella (Thomson, 1871)

Saldula saltatoria (Linnaeus, 1758)

\section{CiMiCOMORPHA}

\section{Tingidae}

Acalypta carinata (Panzer, 1806)

Acalypta gracilis (Fieber, 1844)

Acalypta marginata (Wolff, 1804)

Agramma atricapillum (Spinola, 1837)

Agramma confusum (Puton, 1879)

Agramma laetum (Fallén, 1807)

Catoplatus carthusianus (Goeze, 1778)

Catoplatus nigriceps Horváth, 1905

Copium clavicorne (Linnaeus, 1758)

Corythucha ciliata (Say, 1832)

Derephysia foliacea (Fallén, 1807)

Dictyla echii (Schrank, 1781)

Dictyla humuli (Fabricius, 1794)

Dictyla lupuli (Herrich-Schäffer, 1839)

Dictyla rotundata (Herrich-Schäffer, 1835)

Elasmotropis testacea (Herrich-Schäffer, 1930)

Lasiacantha capucina (Germar, 1836)

Lasiacantha gracilis (Herrich-Schäffer, 1830)

Lasiacantha hermani Vásárhelyi, 1977

Monosteira unicostata (Mulsant et Rey, 1852)

Oncochila scapularis (Fieber, 1844)

Oncochila simplex (Herrich-Schäffer, 1830)

Physatocheila costata (Fabricius, 1794)

Physatocheila dumetorum (Herrich-Schäffer, 1838)

Stephanitis pyri (Fabricius, 1822)

Tingis ampliata (Herrich-Schäffer, 1839)

Tingis auriculata (Costa, 1843)

Tingis cardui (Linnaeus, 1758)

Tingis crispata (Herrich-Schäffer, 1838)

Tingis pilosa Hummel, 1825

Tingis reticulata Herrich-Schäffer, 1835

Microphysidae

Loricula pselaphiformis Curtis, 1833

Myrmedobia exilis (Fallén, 1807)

\section{Miridae}

Bryocorinae

Bryocoris pteridis (Fallén, 1807)

Monalocoris filicis (Linnaeus, 1758)

\section{Deraeocorinae}

Alloeotomus germanicus E. Wagner, 1939

Deraeocoris lutescens (Schilling, 1836)

Deraeocoris olivaceus (Fabricius, 1776)

Deraeocoris ruber (Linnaeus, 1758)

Deraeocoris serenus (Douglas \& Scott, 1868)

Deraeocoris trifasciatus (Linnaeus, 1767)

\section{Dicyphinae}

Campyloneura virgula (Herrich-Schäffer, 1835)

Dicyphus constrictus (Boheman, 1852)

Dicyphus errans (Wolff, 1804)

Dicyphus globulifer (Fallén, 1829)

Dicyphus pallidus (Herrich-Schäffer, 1835)

Dicyphus stachydis Reuter, 1883

\section{Mirinae}

Acetropis carinata (Herrich-Schäffer, 1842)

Acetropis longirostris (Puton, 1875)

Adelphocoris lineolatus (Goeze, 1778)

Adelphocoris quadripunctatus (Fabricius, 1794)

Adelphocoris seticornis (Fabricius, 1775)

Adelphocoris ticinensis (Meyer-Dür, 1843)

Adelphocoris vandalicus (Rossi, 1790)

Agnocoris rubicundus (Fallén, 1829)

Apolygus limbatus (Fallén, 1829)

Apolygus lucorum (Meyer-Dür, 1843)

Apolygus spinolai (Meyer-Dür, 1841)

Calocoris affinis (Herrich-Schäffer, 1839)

Calocoris roseomaculatus (De Geer, 1773)

Capsodes gothicus (Linnaeus, 1758)

Capsodes mat (Rossi, 1790)

Capsus ater (Linnaeus, 1758)

Charagochilus gyllenhali (Fallén, 1807)

Closterotomus biclavatus (Herrich-Schäffer, 1835)

Closterotomus fulvomaculatus (DeGeer, 1773)

Closterotomus norwegicus (Gmelin, 1788)

Dionconotus c. confluens Hoberlandt, 1945

Grypocoris sexguttatus (Fabricius, 1776)

Leptopterna dolabrata (Linnaeus, 1758)

Leptopterna ferrugata (Fallén, 1807)

Liocoris tripustulatus (Fabricius, 1781)

Lygocoris pabulinus (Linnaeus, 1761)

Lygus gemellatus (Herrich-Schäffer, 1835)

Lygus pratensis (Linnaeus, 1758)

Lygus rugulipennis Poppius, 1911

Megacoelum infusum (Herrich-Schäffer, 1839)

Megaloceroea recticornis (Geoffroy, 1785)

Mermitelocerus schmidti (Fieber, 1836)

Miris striatus (Linnaeus, 1758)

Myrmecoris gracilis (F. Sahlberg, 1848)

Notostira elongata (Geoffroy, 1785)

Notostira erratica (Linnaeus, 1758)

Orthops campestris (Linnaeus, 1758)

Orthops kalmii (Linnaeus, 1758) 
Pantilius tunicatus (Fabricius, 1781) Phytocoris dimidiatus Kirschbaum, 1856 Phytocoris longipennis Flor, 1860

Phytocoris meridionalis Herrich-Schäffer, 1835 Phytocoris reuteri Saunders, 1875

Phytocoris singeri E. Wagner, 1954 Phytocoris tiliae (Fabricius, 1776) Phytocoris ulmi (Linnaeus, 1758) Phytocoris varipes Boheman, 1852 Polymerus brevicornis (Reuter, 1878) Polymerus cognatus (Fieber, 1858) Polymerus holosericeus (Hahn, 1831) Polymerus nigritus (Fallén, 1829) Polymerus unifasciatus (Fabricius, 1794) Polymerus vulneratus (Panzer, 1806) Rhabdomiris s. striatellus (Fabricius, 1794) Stenodema calcaratum (Fallén, 1807) Stenodema laevigatum (Linnaeus, 1758) Stenotus binotatus (Fabricius, 1794) Trigonotylus caelestialium (Kirkaldy, 1902) Trigonotylus pulchellus (Hahn, 1834)

\section{Halticinae}

Halticus a. apterus (Linnaeus, 1761) Halticus luteicollis (Panzer, 1805) Orthocephalus saltator (Hahn, 1835) Orthocephalus vittipennis (Herrich-Schäffer, 1835) Piezocranum simulans Horváth, 1877 Strongylocoris leucocephalus (Linnaeus, 1758) Strongylocoris luridus (Fallén, 1807)

\section{Orthotylinae}

Blepharidopterus angulatus (Fallén, 1807)

Cyllecoris histrionius (Linnaeus, 1767)

Dryophilocoris flavoquadrimaculatus (De Geer, 1773)

Dryophilocoris luteus (Herrich-Schäffer, 1836) Globiceps flavomaculatus (Fabricius, 1794)

Globiceps fulvicollis Jakovlev, 1877 Globiceps sphaegiformis (Rossi, 1790) Heterocordylus erythrophthalmus (Hahn, 1831) Heterocordylus tibialis (Hahn, 1831) Heterocondylus tumidicomis (Herrich-Schäffer, 1835) Heterotoma meriopterum (Scopoli, 1763)

Malacocoris chlorizans (Panzer, 1794)

Orthotylus flavosparsus (F. Sahlberg, 1842) Orthotylus marginalis Reuter, 1884

Orthotylus nassatus (Fabricius, 1787)

Orthotylus prasinus (Fallén, 1829)

Orthotylus schoberiae Reuter, 1876

Orthotylus tenellus (Fallén, 1829)

Orthotylus viridinervis (Kirschbaum, 1856)

\section{Pilophorinae}

Pilophorus clavatus (Linnaeus, 1767)

Pilophorus confusus (Kirschbaum, 1856)

Pilophorus perplexus (Douglas \& Scott, 1875)

\section{Hallodapinae}

Hallodapus montandoni (Reuter, 1895)

Systellonotus triguttatus (Linnaeus, 1767)

Phylinae

Amblytylus albidus (Hahn, 1834)

Amblytylus glaucicollis Kerzhner, 1977

Amblytylus nasutus (Kirschbaum, 1856)

Atractotomus mali (Meyer-Dür, 1843)

Campylomma annulicorne (Signoret, 1865)

Campylomma verbasci (Meyer-Dür, 1843)

Chlamydatus pulicarius (Fallén, 1807)

Chlamydatus pullus Reuter, 1870

Compsidolon salicellum (Meyer-Dür, 1843)

Criocoris crassicornis (Hahn, 1834)

Criocoris nigripes Fieber, 1861

Criocoris sulcicornis (Kirschbaum, 1856)

Europiella artemisiae (Becker, 1864)

Harpocera thoracica (Fallén, 1807)

Hoplomachus thunbergi (Fallén, 1807)

Lopus decolor (Fallén, 1807)

Macrotylus herrichi Reuter, 1873

Macrotylus solitarius (Meyer-Dür, 1843)

Megalocoleus exsanguis (Herrich-Schäffer, 1835)

Megalocoleus hungaricus E. Wagner, 1944

Monosynamma bohemani (Fallén, 1829)

Oncotylus setulosus (Herrich-Schäffer, 1839)

Orthonotus cylindricollis (Costa, 1852)

Orthonotus rufifrons (Fallén, 1807)

Phylus coryli (Linnaeus, 1758)

Phylus melanocephalus (Linnaeus, 1767)

Plagiognathus arbustorum (Fabricius, 1794)

Plagiognathus bipunctatus Reuter, 1883

Plagiognathus chrysanthemi (Wolff, 1804)

Plagiognathus fulvipennis (Kirschbaum, 1856)

Psallus albicinctus (Kirschbaum, 1856)

Psallus anaemicus Seidenstücker, 1966

Psallus lepidus Fieber, 1858

Psallus pardalis Seidenstücker, 1966

Psallus perrisi (Mulsant, 1852)

Psallus variabilis (Fallén, 1829)

Salicarus roseri (Herrich-Schäffer, 1839)

\section{Nabidae}

Prostemmatinae

Prostemma aeneicolle Stein, 1857

\section{Nabinae}

Himacerus apterus (Fabricius, 1798)

Himacerus boops (Schiödte, 1870)

Himacerus mirmicoides (O. Costa, 1834)

Nabis brevis Scholtz, 1847

Nabis ferus (Linnaeus, 1758)

Nabis limbatus (Dahlbom, 1850)

Nabis pseudoferus Remane, 1949

Nabis punctatus Costa, 1847

Nabis rugosus (Linnaeus, 1758) 


\section{Anthocoridae}

Anthocorinae

Anthocoris confusus Reuter, 1889

Anthocoris limbatus Fieber, 1836

Anthocoris minki Dohrn, 1860

Anthocoris nemoralis (Fabricius, 1794)

Anthocoris nemorum (Linnaeus, 1761)

Orius laticollis (Reuter, 1884

Orius majusculus (Reuter, 1879)

Orius minutus (Linnaeus, 1758)

Orius niger Wolff, 1804

Orius vicinus Ribaut, 1923

\section{Lyctocorinae}

Dufouriellus ater (Dufour, 1833)

Dysepicritus rufescens (Costa, 1843 )

Lyctocoris campestris (Fabricius, 1794)

Lyctocoris dimidiatus (Spinola, 1837)

Xylocoris cursitans (Fallén, 1807)

Cimicidae

Oeciacus hirundinis (Jenyns, 1839)

\section{Reduviidae}

\section{Emesinae}

Empicoris culiciformis (De Geer, 1773)

Metapterus linearis Costa, 1860

Peiratinae

Peirates hybridus (Scopoli, 1763)

\section{Stenopodainae}

Pygolampis bidentata (Goeze, 1778)

\section{Reduviinae}

Reduvius personatus (Linnaeus, 1758)

\section{Harpactorinae}

Coranus kerzhneri P. Putshkov, 1982

Coranus subapterus (De Geer, 1773)

Nagusta goedeli (Kolenati, 1856)

Rhynocoris annulatus (Linnaeus, 1758)

Rhynocoris iracundus (Poda, 1761)

Phymatinae

Phymata crassipes (Fabricius, 1775)

PENTATOMOMORPHA

Aradidae

Aneurus avenius Dufour, 1833

Aradus betulae (Linnaeus, 1758)

Aradus cinnamomeus (Panzer, 1794)

Aradus conspicuus (Herrich-Schäffer, 1835)

Aradus depressus (Fabricius, 1794)

Aradus ribauti Wagner, 1956

\section{Piesmatidae}

Piesma capitatum (Wolff, 1804)

Piesma maculatum (Laporte, 1832)

Piesma salsolae (Becker, 1867)

\section{Berytidae}

Berytinae

Berytinus clavipes (Fabricius, 1775)

Berytinus geniculatus (Horváth, 1885)

Berytinus minor (Herrich-Schäffer, 1835)

Berytinus montivagus (Meyer-Dür, 1841)

Neides tipularius (Linnaeus, 1758)

Metacanthinae

Metatropis rufescens (Herrich-Schäffer, 1835)

\section{Lygaeidae}

Lygaeinae

Lygaeosoma sardeum Spinola, 1837

Lygaeus equestris (Linnaeus, 1758)

Lygaeus simulans Deckert, 1985

Spilostethus pandurus (Scopoli, 1763)

Spilostethus saxatilis (Scopoli, 1763)

\section{Orsillinae}

Nysius ericae (Schilling, 1829)

Nysius helveticus (Herrich-Schäffer, 1850)

Nysius senecionis (Schilling, 1829)

Nysius thymi (Wolff, 1804)

Orsillus depressus Dallas, 1852

Ortholomus punctipennis (Herrich-Schäffer, 1839)

Ischnorrhynchinae

Kleidocerys resedae (Panzer, 1797)

\section{Cyminae}

Cymus claviculus (Fallén, 1807)

Cymus glandicolor (Hahn, 1831)

Cymus melanocephalus Fieber, 1861

Blissinae

Dimorphopterus spinolae (Signoret, 1857)

Ischnodemus sabuleti (Fallén, 1829)

\section{Henestarinae}

Henestaris halophilus (Burmeister, 1835)

\section{Geocorinae}

Geocoris ater (Fabricius, 1787)

Geocoris dispar (Waga, 1839)

Geocoris erythrocephalus (Lepeletier \& Serville, 1825)

Artheneinae

Chilacis typhae (Perris, 1857)

\section{Heterogastrinae}

Heterogaster artemisiae Schilling, 1829

Platyplax salviae (Schilling, 1829) 


\section{Oxycareninae}

Brachyplax tenuis (Mulsant et Rey, 1852)

Camptotelus lineolatus (Schilling, 1829)

Macroplax fasciata (Herrich-Schäffer, 1835)

Macroplax preyssleri (Fieber,1836)

Metopoplax origani (Kolenati, 1845)

Oxycarenus modestus (Fallén, 1829)

Oxycarenus pallens (Herrich-Schäffer, 1850)

Tropidophlebia costalis (Herrich-Schäffer, 1850)

\section{Rhyparochrominae}

Acompus rufipes (Wolff, 1804)

Aellopus atratus (Goeze, 1778)

Beosus maritimus (Scopoli, 1763)

Beosus quadripunctatus (Müller, 1766)

Drymus brunneus (F. Sahlberg, 1848)

Drymus latus Douglas et Scott, 1871

Drymus ryei Saunders, 1892

Drymus sylvaticus (Fabricius, 1775)

Emblethis ciliatus Horváth, 1875

Emblethis denticollis Horváth, 1878

Emblethis griseus (Wolff, 1802)

Emblethis verbasci (Fabricius, 1803)

Eremocoris plebejus (Fallén, 1807)

Eremocoris podagricus (Fabricius, 1775)

Gastrodes grossipes (De Geer, 1773)

Graptopeltus validus Horváth, 1875

Graptopeltus lynceus (Fabricius, 1775)

Megalonotus praetextatus (Herrich-Schäffer, 1835)

Megalonotus sabulicola (Thomson, 1870)

Pachybrachius fracticollis (Schilling, 1829)

Peritrechus geniculatus (Hahn, 1831)

Peritrechus gracilicornis (Puton, 1877)

Peritrechus lundii (Gmelin, 1789)

Peritrechus nubilus (Fallén, 1807)

Plinthisus brevipennis (Latreille, 1807)

Plinthisus pusillus (Scholtz, 1846)

Pterotmetus staphyliniformis (Schilling, 1829)

Raglius alboacuminatus (Goeze, 1778)

Rhyparochromus pini (Linnaeus, 1758)

Rhyparochromus vulgaris (Schilling, 1829)

Scolopostethus affinis (Schilling, 1829)

Scolopostethus decoratus (Hahn, 1831)

Scolopostethus pictus (Schilling, 1829)

Scolopostethus pilosus Reuter, 1874

Scolopostethus thomsoni Reuter, 1874

Sphragisticus nebulosus (Fallén, 1807)

Stygnocoris fuligineus (Geoffroy, 1785)

Stygnocoris pygmaeus (F. Sahlberg, 1848)

Stygnocoris rusticus (Fallén, 1807)

Stygnocoris sabulosus (Schilling, 1829)

Trapezonotus arenarius (Linnaeus, 1758)

Trapezonotus dispar Stal, 1872

Trapezonotus ullrichi (Fieber, 1836)

Tropistethus holosericeus (Scholtz, 1846)

Xanthochilus quadratus (Fabricius, 1798)
Pyrrhocoridae

Pyrrhocoris apterus (Linnaeus, 1758)

Pyrrhocoris marginatus (Kolenati, 1845)

\section{Stenocephalidae}

Dicranocephalus agilis (Scopoli, 1763)

Dicranocephalus albipes (Fabricius, 1781)

Dicranocephalus medius (Mulsant et Ray, 1870)

\section{Coreidae}

Coreinae

Coreus marginatus (Linnaeus, 1758)

Gonocerus acuteangulatus (Goeze, 1778)

Gonocerus juniperi (Herrich-Schäffer, 1839)

Syromastes rhombeus (Linnaeus, 1767)

\section{Spathocerinae}

Spathocera laticornis (Schilling, 1829)

Spathocera lobata (Herrich-Schäffer, 1840)

Spathocera tuberculata Horváth, 1882

\section{Arenocorinae}

Arenocoris falleni (Schilling, 1829)

Ceraleptus gracilicornis (Herrich-Schäffer, 1835)

Ceraleptus lividus Stein, 1858

Coriomeris denticulatus (Scopoli, 1763)

Coriomeris scabricornis (Panzer, 1809)

Alydidae

Alydus calcaratus (Linnaeus, 1758)

Camptopus lateralis (Germar, 1817)

\section{Rhopalidae}

Rhopalinae

Brachycarenus tigrinus (Schilling, 1817)

Corizus hyoscyami (Linnaeus, 1758)

Liorhyssus hyalinus (Fabricius, 1794)

Rhopalus conspersus (Fieber, 1837)

Rhopalus distinctus (Signoret, 1859)

Rhopalus maculatus (Fieber, 1837)

Rhopalus parumpunctatus (Schilling, 1817)

Rhopalus subrufus (Gmelin, 1788)

Stictopleurus abutilon (Rossi, 1790)

Stictopleurus crassicornis (Linnaeus, 1758)

Stictopleurus punctatonervosus (Goeze, 1778)

\section{Myrminae}

Chorosoma gracile Josifov, 1968

Myrmus miriformis (Fallén, 1807)

Plataspidae

Coptosoma mucronatum Seidenstücker, 1963

Coptosoma scutellatum (Geoffroy, 1785)

\section{Thyreocoridae}

Thyreocoris scarabaeoides (Linnaeus, 1758) 
Cydninae

Aethus nigritus (Fabricius, 1794)

Cydnus aterrimus (Förster, 1771)

Geotomus elongatus (Herrich-Schäffer, 1839)

Geotomus punctulatus (Costa, 1847)

Sehirinae

Canthophorus dubius (Scopoli, 1763)

Canthophorus melanopterus (Herrich-Schäffer, 1835)

Legnotus limbosus (Geoffroy, 1785)

Legnotus picipes (Fallén, 1807)

Ochetostethus opacus (Scholtz, 1847)

Tritomegas bicolor (Linnaeus, 1758)

Tritomegas sexmaculatus (Rambur, 1842)

\section{Scutelleridae}

Eurygaster austriaca (Schrank, 1776)

Eurygaster maura (Linnaeus, 1758)

Eurygaster testudinaria (Geoffroy, 1785)

Odontoscelis fuliginosa (Linnaeus, 1761)

Odontoscelis lineola Rambur, 1842

Odontotarsus purpureolineatus (Rossi, 1790)

Odontotarsus robustus Jakovlev, 1883

Psacasta exanthematica (Scopoli, 1763)

\section{Pentatomidae}

Podopinae

Derula flavoguttata Mulsant et Rey, 1856

Graphosoma lineatum (Linnaeus, 1758)

Podops curvidens Costa, 1847

Podops inuncta (Fabricius, 1775)

Ventocoris trigonus (Krynicki, 1871)

Vilpianus galii (Wolff, 1802)

\section{Pentatominae}

Aelia acuminata (Linnaeus, 1758)

Aelia rostrata Boheman, 1852

Antheminia lunulata (Goeze, 1778)

Carpocoris fuscispinus (Boheman, 1850)

Carpocoris pudicus (Poda, 1761)

Carpocoris purpureipennis (De Geer, 1773)

Chlorochroa juniperina (Linnaeus, 1758)
Codophila varicornis (Jakovlev, 1874)

Dolycoris baccarum (Linnaeus, 1758)

Dyroderes umbraculatus (Fabricius, 1775)

Eurydema dominulus (Scopoli, 1763)

Eurydema oleraceum (Linnaeus, 1758)

Eurydema ornatum (Linnaeus, 1758)

Eurydema ventrale Kolenati, 1846

Eusarcoris aeneus (Scopoli, 1763)

Eusarcoris fabricii Kirkaldy, 1904

Eusarcoris ventralis (Westwood, 1837)

Holcostethus vernalis (Wolff, 1804)

Menaccarus arenicola (Scholtz, 1846)

Neottiglossa leporina (Herrich-Schäffer, 1830)

Neottiglossa pusilla (Gmelin, 1789)

Palomena prasina (Linnaeus, 1761)

Pentatoma rufipes (Linnaeus, 1758)

Piezodorus lituratus (Fabricius, 1794)

Rhaphigaster nebulosa (Poda, 1761)

Rubiconia intermedia (Wolff, 1811)

Sciocoris cursitans (Fabricius, 1794)

Sciocoris distinctus Fieber, 1851

Sciocoris macrocephalus Fieber, 1851

Sciocoris microphthalmus Flor, 1860

Sciocoris sulcatus Fieber, 1851

Stagonomus amoenus (Brullé, 1832)

Stagonomus pusillus (Herrich-Schäffer, 1830)

Staria lunata (Hahn, 1834)

\section{Asopinae}

Arma custos (Fabricius, 1794)

Picromerus bidens (Linnaeus, 1758)

Pinthaeus sanguinipes (Fabricius, 1781)

Rhacognathus punctatus (Linnaeus, 1758)

Zicrona coerulea (Linnaeus, 1758)

\section{Acanthosomatidae}

Acanthosoma haemorrhoidale (Linnaeus, 1758)

Cyphostethus tristriatus (Fabricius, 1787)

Elasmostethus interstinctus (Linnaeus, 1758)

Elasmucha grisea (Linnaeus, 1758) 
1. táblázat: A poloskafajok száma Somogyban és Magyarországon, és a helyi fauna százalékos részesedése a hazai faunából

\begin{tabular}{|c|c|c|c|}
\hline Család & Somogy & Magyaro. & $\%$ \\
\hline Dipsocoromorpha & 1 & 4 & 25 \\
\hline Cryptostem matidae & 1 & 1 & 100 \\
\hline Dipsocoridae & 0 & 3 & 0 \\
\hline Nepomorpha & 21 & 33 & 63,6 \\
\hline Aphelochiridae & 0 & 1 & 0 \\
\hline Corixidae & 15 & 23 & 65,2 \\
\hline Naucoridae & 1 & 1 & 100 \\
\hline Nepidae & 2 & 2 & 100 \\
\hline Notonectidae & 2 & 5 & 40 \\
\hline Pleidae & 1 & 1 & 100 \\
\hline Gerromorpha & 12 & 21 & 57,1 \\
\hline Gerridae & 6 & 9 & 66,7 \\
\hline Hebridae & 1 & 2 & 50 \\
\hline Hydrom etridae & 2 & 2 & 100 \\
\hline Mesoveliidae & 1 & 2 & 50 \\
\hline Veliidae & 2 & 6 & 33,3 \\
\hline Leptopodomorpha & 10 & 19 & 52,6 \\
\hline Leptopodidae & 0 & 1 & 0 \\
\hline Saldidae & 10 & 18 & 55,6 \\
\hline Cimicomorpha & 211 & 415 & 50,8 \\
\hline Anthocoridae & 15 & 31 & 48,4 \\
\hline Cimicidae & 1 & 3 & 33,3 \\
\hline Microphysidae & 2 & 5 & 40 \\
\hline Miridae & 141 & 276 & 51,1 \\
\hline Nabidae & 10 & 16 & 62,5 \\
\hline Reduviidae & 11 & 20 & 55 \\
\hline Tingidae & 31 & 64 & 48,4 \\
\hline Pentatomomorpha & 193 & 334 & 57,8 \\
\hline Acanthosomatidae & 4 & 7 & 57,1 \\
\hline Alydidae & 2 & 3 & 66,7 \\
\hline Aradidae & 6 & 22 & 27,3 \\
\hline Berytidae & 6 & 15 & 40 \\
\hline Coreidae & 12 & 23 & 52,2 \\
\hline Cydnidae & 11 & 20 & 55 \\
\hline Lygaeidae & 76 & 130 & 58,4 \\
\hline Pentatomidae & 44 & 66 & 66,7 \\
\hline Piesmatidae & 3 & 7 & 42,9 \\
\hline Plataspidae & 2 & 2 & 100 \\
\hline Pyrrhocoridae & 2 & 2 & 100 \\
\hline Rhopalidae & 13 & 17 & 76,5 \\
\hline Scutelleridae & 8 & 15 & 53,3 \\
\hline Stenocephalidae & 3 & 3 & 100 \\
\hline Thyreocoridae & 1 & 2 & 50 \\
\hline Összesen & 448 & 826 & 54,2 \\
\hline
\end{tabular}


A felsorolt fajokat családonként összesítve összevetettem a családok jelenleg ismert hazai fajszámával (1. táblázat). A legtöbb nagyobb családból hasonló arányban (kb. 45-60\%) kerültek elő Somogy megyében a fajok. Ahol ennél magasabb volt az arány, ott vagy sok gyakori fajt tartalmaz a család (Rhopalidae) vagy feltúnô, nagy fajokkal jellemezhetố (Pentatomidae). Ahol pedig jóval alacsonyabb az arány, ott vagy nagyon apró (Dipsocoridae) vagy speciális módszerekkel gyújthetố fajok vannak (kéreg alatt élốk: Aradidae; paraziták: Cimicidae).

A 2. táblázatban a hazai fajok elterjedési típusait az áttekinthetőség kedvé-

2. táblázat: A hazai és a Somogyból elốkerült fajok elterjedési típusai

\begin{tabular}{|l|c|c|c|c|}
\hline \multicolumn{1}{|c|}{ Öszesített elterjedési típusok } & Somogy & Magyaro. & $\%$ & $\% / \% *$ \\
\hline Európai & 51 & 133 & 38,3 & 0,71 \\
\hline Euroturáni & 5 & 11 & 45,5 & 0,83 \\
\hline Euroszibériai & 76 & 135 & 56,3 & 1,04 \\
\hline Holarktikus & 32 & 44 & 72,7 & 1,35 \\
\hline Kozmopolita & 6 & 8 & 75 & 1,4 \\
\hline Holomediterrán & 13 & 32 & 40,6 & 0,65 \\
\hline Holomediterrán-turáni & 12 & 32 & 37,5 & 0,69 \\
\hline Euromediterrán & 35 & 57 & 61,4 & 1,14 \\
\hline Észak-mediterrán & 11 & 34 & 32,4 & 0,6 \\
\hline Palearktikus & 87 & 110 & 79,1 & 1,48 \\
\hline Pontomediterrán & 13 & 47 & 27,7 & 0,51 \\
\hline Pontomediterrán-turáni & 3 & 22 & 13,6 & 0,25 \\
\hline Dél-euroszibériai & 20 & 35 & 57,1 & 1,05 \\
\hline Nyugat-euroszibériai & 13 & 23 & 56,5 & 1,05 \\
\hline Nyugat-palearktikus & 73 & 106 & 68,9 & 1,27 \\
\hline Mindebb õl boreomontán & 15 & 48 & 31,3 & 0,58 \\
\hline
\end{tabular}

ért némileg leegyszerúsítve összevetem a Somogy megyében elókerült fajok elterjedési típusaival. Ez természetesen némi hibával jár, továbbá néhány fajnak még bizonyára nem ismerjük jól az elterjedését, de egyes százalékok összehasonlítása érdekes lehet.

Kiemelkedően magas a palearktikus, kozmopolita, holarktikus és talán a nyugat-palearktikus fajok aránya. Ez érthetô, hiszen e fajok széles földrajzi elterjedése általában logikusan széles ökológiai tứróképességgel jár együtt, így szinte mindenütt gyakoriak.

A másik végletet a pontomediterrán (pontomediterrán-turáni) és észak-mediterrán fajoknál tapasztalhatjuk. E fajok igen alacsony aránya arra utalna, hogy Somogy megye déli fekvése ellenére sem bővelkedik délies klímájú vagy mikroklímájú területekben (a többi mediterrán jellegú faj is az átlagosnál alacsonyabb arányban van jelen), de errôl még lejjebb szó lesz. Természetesen a boreomontán fajok aránya is alacsonyabb az átlagosnál, hiszen a megye területén hegység nincsen.

Ha azt vizsgálom, hogy az elterjedési típus (csoport) részesedése a somogyi

* Somogy megye faunájából az adott elterjedési típus(csoport) részesedése / a magyar faunából az adott elterjedési típus(csoport) részesedése (pl. palearktikus fajoknál (110:830)/(87:448) az utolsó oszlopbeli számadat háttere). 
összfaunából mennyi a hazai összfaunából való részesedéséhez képest, akkor a 2. táblázat utolsó oszlopának értékeit kapom. Ha ez a mutató egynél nagyobb, akkor a csoport felülreprezentált hazai arányához képest, ha kisebb, kevesebb került eló belólük, mint a hazai arány alapján várható lett volna. Persze ez a mutató is korrigálandó a fentebb leírtak alapján (például a palearktikus fajok aránya a többi hazai faunafelmérésnél (Kiskunsági NP, Hortobágyi NP, Bátorligeti TT, Órségi TK, Dráva-mente, Villányi-hgys., Síkfókúti TT) is jócskán meghaladta az l-et, míg pl. a pontomediterrán fajoké sehol nem érte el). Ami viszont a felsorolt védett területek között is figyelemreméltó, hogy a föntebb leírtakkal ellentétben (bár a terület heterogén jellege miatt szélsőséges érték előfordulása nem várható) a legmagasabbak között van a mediterrán, euromediterrán és pontomediterrán fajok aránya. Ezek szerint tehát mégis erôsebben mediterrán jellegú a megye poloskafaunája, mint az ország nagyobb része.

A magasabbak között van a dél- és a nyugat-euroszibériai fajok aránya is, de itt nincs számottevő különbség az arányok között. Ezzel szemben a palearktikus fajok aránya elmarad a legtöbb faunafelmérésnél tapasztalttól (noha a táblázatban e fajcsoportnál van a legmagasabb érték). Ennek pedig az lehet az oka, hogy mivel a palearktikus fajok a fentebb írtak alapján a legáltalánosabban elterjedt fajok közé tartoznak, már kisebb ráfordítással is nagy számban kerülnek elő, és minél több fajt mutatunk ki, annál több lesz a mảs jellegú fajok aránya. Márpedig a felsorolt hazai faunafelmérések közül Somogy megyéből került elő a legtöbb faj, és ezt csak a Kiskunsági Nemzeti Park közelíti meg (csak itt volt a palearktikus fajok aránya a Somogy megyeinél alacsonyabb).

\section{Irodalom}

Benedek, P. 1966: A magyarországi Eurydemákról (Heteroptera, Pentatomidae) II. A hazai Eurydema fajok faunisztikai, etológiai adatai és földrajzi elterjedése. Állatt. Közl. 53: 33-41.

BenedeK, P. 1967: Faunisztikai, etológiai és tápnövény adatok magyarországi Pentatomoidea (Heteroptera) fajokról. Folia ent. hung. 20: 475-519.

Benedek, P. 1968: Revision on the families Reduviidae and Phymatidae in the Carpathian Basin with the description of a new species from Hungary (Heteroptera). Folia ent. hung., 21: 297-318.

BENEDEK, P. 1969: A Nabidae család (Heteroptera) fajainak elterjedése a Kárpát-medencében. Állatt. Közl. 56: 7-16.

BenedeK, P. 1970: The semiaquatic Heteroptera in the Carpathian Basin with notes on the distribution and the phenology of the species. Faun. Abh. Staatl. Mus. Tierkunde Dresden, 3: 27-49.

Földessy, M. 1992: Adatok a Boronka-melléki Tájvédelmi Körzet poloska (Heteroptera) faunájához. In: Uherkovich, Á. (szerk.): A Boronka-melléki Tájvédelmi Körzet élôvilága. Dunántúli Dolgozatok Természettudományi Sorozat 7: 101-106.

HALÁSZFY, É. Cs. 1954: Magyarország és a környező területek Brachyplatida és Cydnida fajainak ökológiája és elterjedése. Folia ent. hung. 7: 93-132.

HALÁSzFY, É. Cs. 1955: Magyarország és a környező területek Scutelleridae (Scutellerinae) fajainak ökológiája és elterjedése. Folia ent. hung. 8: 73-94.

Horváth, G. 1900: Ordo Hemiptera. In: A Magyar Birodalom Állatvilága (Fauna Regni Hungariae). A K. M. Természettud. Társ., Budapest. 64 pp.

KondorosY, E. 1999: Checklist of the Hungarian bug fauna (Heteroptera). Folia ent. hung. 60:125-152.

Kondorosy, E. - Földessy, M. 1998: Adatok a Duna - Dráva Nemzeti Park Dráva menti területei poloska (Heteroptera) faunájához - In: Uherkovich, Á. (szerk.): Dunántúli Dolgozatok Természetudományi Sorozat 9: 159-176. 
Soós, Á. 1959: Revision und Ergänzungen zum Heteropteren-Teil des Werkes „Fauna Regni Hungariae" I. 1. Corixidae. Ann. Hist.-nat. Mus. Nat. Hung., 51: 429-441.

Soós, Á. 1973: Új és ritka bodobács-fajok a magyar faunában. I. (Heteroptera: Lygaeidae). Folia ent. hung. 26: 373-384.

VÁSÁRHELYI, T. 1974a: Új és kevéssé ismert csipkéspoloskák a magyar faunában (Heteroptera: Tingidae). Folia ent. hung. 27: 231-234.

VÁSÁRHELYI, T. 1974b: Új poloskafajok a magyar faunában (Heteroptera: Pentatomoidea). Folia ent. hung. 27: 227-230.

VÁSÁRHElYI, T. 1979: Madár- és emlósfészkekből futtatott poloskák (Heteroptera). Folia ent. hung. 32: 229-230.

VÁSÁRHELYI, T. 1985: A barcsi borókás poloskafaunájának alapvetése (Heteroptera) - Dunántúli Dolgozatok Természettudományi Sorozat 5: 101-104.

\title{
Bug fauna of Somogy county (Heteroptera)
}

\section{ELŐ́D KONDOROSY}

The checklist of the currently known bug species of Somogy county is based on the author's collected material, the available insect collections of the museums and the limited literature written on the county's fauna.

Altogether 448 species were proved to be local to the county, which is more than $54 \%$ of the presently known 826 species in Hungary.

Five of these species are recorded only in Somogy county.

Approximately 200 more species are expected to be in the county, which have not been found yet, due to their rarity, their special habitats or simply by chance.

The proportion of the Mediterranean (Holo-, Ponto- Euromediteranean) fauna elements occurring in Somogy county is higher compared to the data provided by most of the faunistical surveys in Hungary.

On the other hand, the Palearctic fauna elements occur in a smaller proportion, since the species with other types of distribution tend to occur in higher number.

\author{
Author's address: \\ Dr. Elöd KONDOROSY \\ University of Veszprém \\ Georgikon Faculty of Agriculture \\ H-8360 Keszthely \\ Deák F. u. 16 \\ HUNGARY
}

